other cause for hydrocephalus was identified and his ependymal cilia can be presumed immotile. Human ependymal cilia are widely distributed throughout the ventricles, particularly the fourth, ${ }^{+}$and continue to beat in a coordinated fashion even after death. ${ }^{5}$ In man their function is unknown but in rats ependymal cilia caused circulating currents in cerebrospinal fluid ${ }^{5}$ and a mutant mouse (hpy/hpy) had generalised ciliary abnormalities, male sterility, and hydrocephalus.' The presence of hydrocephalus was noted in a previous series of patients with Kartagener's syndrome, although the possible significance was not recognised. In another series, a patient with dextrocardia and chronic sputum production developed hydrocephalus requiring a Torkildsen shunt ( $\mathrm{Dr}$ A Childs, personal communication). Cerebral computed tomography of 7 patients with Kartagener's syndrome yielded equivocal results, although minor abnormalities of ventricular size were noted in two patients. ${ }^{1}$ The association has not. however, been reported in any other major series. Clearly hydrocephalus is not a constant feature of primary ciliary dyskinesia nor do we suggest ciliary dyskinesia is important in the pathogenesis of most cases of hydrocephalus. It may, however, be a contributory embryological factor. Since secondary damage to the ependymal ciliary system is well described in hydrocephalus, ${ }^{4}$ it is only when a generalised ciliary abnormality is present that a causal relation can be considered.

M G is supported by the Asthma Research Council and the work was supported by Action Research-the National Fund for Research into Crippling Diseases and the Chest. Heart and Stroke Association.

\section{References}

Afzelius BA. The immotile-cilia syndrome and other ciliary discases. Int Rev Exp Pathol 1979:19:1-43.

2 Andersen IB. Camner P. Jensen PL. Philipson K. Proctor DF Nasal clearance in monozygotic twins. Am Rev Respir Dis 1974:110:301-5.

${ }^{3}$ Rutland J. Cole PJ. Non-invasive sampling of nasal cilia for measurement of beat frequency and study of ultrastructure. Lancet 198();ii:564-5.

4 Bannister CM. Chapman SA. Ventricular ependyma of normal and hydrocephalic subjects: a scanning electronmicroscopic study. Dev Med Child Neurol 1980;22:725-35.

5 Worthington WC. Cathcart RS. Ciliary currents on ependymal surfaces. Ann NY Acad Sci 1965:130:944-50.

6 Olsen AM. Bronchiectasis and dextrocardia. Am Rev Tuherc $1943: 47: 435-9$.

Correspondence to Dr M A Greenstone. Host Defence Unit, Department of Medicine, Cardiothoracic Institute, Brompton Hospital, Fulham Road, London. SW3 6HP.

Received 20 January 1984

\title{
Late presentation of haemorrhagic disease of the newborn
}

\author{
G ALPAN, A AVITAL, O PELEG, AND Y DGANI \\ Department of Pediatrics, Hadassah University Hospital, Jerusalem, Israel
}

SUMMARY A 9 week old infant presented with bleeding due to vitamin $\mathrm{K}$ deficiency. He had not been given vitamin $\mathrm{K}$ after birth but there was no associated risk factor for deficiency and he had not bled from circumcision performed at 8 days of age.

Haemorrhagic disease of the newborn caused by vitamin $\mathrm{K}$ deficiency occurs in the first few days of life. Where prophylactic vitamin $K$ is not given presentation after the neonatal period is associated with breast feeding, diarrhoea, malabsorptive states, or enteral antibiotics. ${ }^{1-3}$ Our patient presented with bleeding caused by vitamin $\mathrm{K}$ deficiency at 9 weeks of age with no evidence of underlying disease.

\section{Case report}

A 61 day old infant was brought to the emergency department because of orange discoloration of his napkin. Urine examination showed numerous urate crystals but no red blood cells or haemoglobin. A blood sample was drawn and the anus examined with a cotton tipped applicator. He was discharged only to return 12 hours later with continuous bleeding from the venipuncture site and rectum.

He had been born after a normal pregnancy and weighed $3050 \mathrm{~g}$ at birth. The mother had taken no drugs during pregnancy and the family history was negative for coagulation disorders. During the first week of life soft stools were noted but there was no diarrhoea; he was discharged from the maternity unit when 6 days old and was fed on ProSobee 
(Mead Johnson). Circumcision was performed at age 8 days and no unusual bleeding was noted at that time or on inspection the following day. He was doing well until admission and no drugs had been given.

On admission to hospital the infant was found to be pale but otherwise thriving and in excellent health. There was bleeding from a venipuncture site and from an anal fissure but there were no other abnormal findings on physical examination. Weight on admission was $4480 \mathrm{~g}$. Laboratory investigations showed a haemoglobin of $7.8 \mathrm{~g} / \mathrm{dl}$ with a platelet count of $776 \times 10^{9} / 1$. Prothrombin time and activated partial thromboplastin time were significantly prolonged (Table) while the thrombin time and serum fibrinogen value were normal. Liver function tests were also within normal limits. Blood was drawn for assay of coagulation factors and the infant was treated with vitamin $\mathrm{K}$ and fresh frozen plasma. Bleeding stopped completely within two hours and the coagulation profile was normal the next day. Qualitative assay of blood drawn on admission showed a considerable deficiency of factors II, VII, IX; a moderate deficiency of factor X; and normal concentrations of factors IV and V. A repeat assay done one week after treatment showed normal concentrations of all coagulation factors. Peripheral blood smear, serum vitamin $E$ value, xylose loading test, and a sweat test for cystic fibrosis were all normal.

Investigation showed that the hospital in which this child was born practices a selective policy of prophylactic vitamin $\mathrm{K}$ administration whereby only infants at high risk are given vitamin $\mathrm{K}$ injections. Since he was a healthy, term infant and ProSobee contains more than sufficient amounts of vitamin $\mathrm{K}$ (as recommended by the American Academy of Pediatrics) he was excluded. Subsequent follow up two months after hospital admission showed him to be thriving, with a normal coagulation profile.

Table Coagulation studies before and after treatment (control values in parentheses)

\begin{tabular}{|c|c|c|}
\hline & On hospital admission & After treatment \\
\hline Prothrombin time & $>58 \mathrm{sec}(13 \mathrm{sec})$ & $13 \mathrm{sec}(12 \mathrm{sec})$ \\
\hline Partial thromboplastin time & $>3 \min (50 \mathrm{sec})$ & $48 \mathrm{sec}(50 \mathrm{sec})$ \\
\hline Thrombin time & $9 \sec (9 \sec )$ & $9 \sec (9 \sec )$ \\
\hline \multicolumn{3}{|l|}{ Coagulation factors } \\
\hline II & Considerably decreased & Normal \\
\hline IV & Normal & Normal \\
\hline V & Normal & Normal \\
\hline VII & Considerably decreased & Normal \\
\hline IX & Considerably decreased & Normal \\
\hline $\mathrm{X}$ & Moderately decreased & Normal \\
\hline
\end{tabular}

\section{Discussion}

This patient was unusual in several aspects. Although he presented at 9 weeks of age, the laboratory investigations clearly implicated vitamin $\mathrm{K}$ deficiency. The infant had none of the predisposing conditions mentioned above associated with vitamin $\mathrm{K}$ deficiency. His diet contained more than enough vitamin $K$ and his weight on admission showed that food intake was good. Malabsorption could also be ruled out. Most surprising is the fact that no excessive bleeding was noted 24 hours after the circumcision.

While decreased concentrations of vitamin $\mathrm{K}$ clotting factors are 'physiological' in neonates there is a wide dispersion in the range of values obtained within this group. It is possible that our infant was born with clotting factor concentrations in the low range of normal for age. Thus, even with a diet rich in vitamin $K$, concentrations at 9 weeks of age were insufficient to withstand the trauma inflicted. He did not bleed from the circumcision site possibly due to the action of tissue thromboplastin which may have been sufficient to offset the lack of vitamin $\mathrm{K}$ associated clotting factors. This has been noted in some infants with severe haemophilia who also do not bleed after circumcision due to the liberation of tissue thromboplastin caused by the pressure of the circumcision clamp. ${ }^{4}$

Many maternity units have stopped the routine administration of vitamin $\mathrm{K}$ to term newborns. ${ }^{56} \mathrm{~A}$ selective policy of giving vitamin $\mathrm{K}$ only to babies considered particularly at risk, including exclusively breast fed babies, has also been recommended. ${ }^{7} \mathrm{We}$ believe, however, that cases such as this, albeit uncommon, serve as a warning against a lax policy of vitamin $\mathrm{K}$ administration.

\section{References}

' Sutherland JM. Glueck HI. Glesser G. Hemorrhagic disease of the newborn. Breast feeding as a necessary factor in the pathogenesis. Am J Dis Child 1967;113:524-33.

2 Goldman HI. Amadio P. Vitamin K deficiency after the newborn period. Pediatrics 1969:44:745-9.

${ }^{3}$ Buchanan GR. Neonatal coagulation: normal physiology and pathophysiology. Clin Haematol 1978:7:85-109.

4 Oski FA, Naiman JL. Hematologic problems in the newborn. 3rd ed. Philadelphia: WB Saunders, 1982:161.

5 Dunn PM. Vitamin K for all newborn babies. Lancet 1982;ii: 770

${ }^{6}$ McNinch AW, Orme RL'E, Tripp JH. Hacmorrhagic disease of the newborn returns. Lancet 1983;i:1089-90.

${ }^{7}$ Anonymous. Vitamin $\mathrm{K}$ and the newborn (editorial). Lancet 1978:i:755-7.

Correspondence to $\mathrm{Dr} \mathrm{G}$ Alpan, Department of Pediatrics, Hadassah University Hospital, Mount Scopus, PO Box 24035, Jerusalem, Israel

Received 22 January 1984 